\title{
The effects of food habits on pregnancy outcome
}

\section{Devdatt Laxman Pitale*}

Department of Obstetrics and Gynecology, INHS Patanjali, Karwar, Karnataka, India

Received: 02 December 2017

Accepted: 30 December 2017

\section{*Correspondence:}

Dr. Devdatt Laxman Pitale,

E-mail: dipu.pitale@gmail.com

Copyright: (c) the author(s), publisher and licensee Medip Academy. This is an open-access article distributed under the terms of the Creative Commons Attribution Non-Commercial License, which permits unrestricted non-commercial use, distribution, and reproduction in any medium, provided the original work is properly cited.

\section{ABSTRACT}

Background: Nutrition during pregnancy plays an important role for an optimum outcome of pregnancy. Maternal undernutrition can lead to poor intrauterine growth and low weight of the baby at birth. Moreover, the leading causes for maternal deaths like hemorrhage and infection are related directly or indirectly to nutrition. The aim of this study was to study the effects of food habits on pregnancy outcome.

Methods: 350 women from the antenatal clinic, who satisfied the criteria were admitted to the study.

Results: The majority of pregnant women belonged to the age group of 21-25 years (47\%) followed by the 26-30 years age group (40\%) and $83 \%$ belonged to the low socioeconomic class. Majority of the babies $(66 \%)$ had the birth weight in the range of $2.5-2.9 \mathrm{~kg}$. There was a significant association ( $\mathrm{p}$ value $<0.05$ ) between the socioeconomic status of the mother, parity and her calorie intake. The present study found a statistically significant association between the maternal nutritional status, the birth weight of the baby and the need for NICU admission ( $p$ value $<0.05)$.

Conclusions: Maternal food habits have significant effects on the pregnancy outcome.

Keywords: Birth weight, Food habits, Nutrition

\section{INTRODUCTION}

An adequate availability of nutrients during gestation is probably the single most important environmental factor influencing pregnancy outcome. ${ }^{1}$ An inadequate supply will risk the well-being of both mother and the conceptus.

A woman with poor nutritional status has an increased risk of complications like anemia and adverse pregnancy outcomes such as postpartum hemorrhage, preterm births and fetal growth retardation which in turn increases the risk of prematurity and low birth weight. The National Family Health Survey-4 (NFHS) indicates that $20.2 \%$ of men and $22.9 \%$ of women are undernourished. ${ }^{2}$ Maternal nutrition is indirectly assessed by her weight gain during pregnancy. According to the guidelines of Institute of Medicine the total weight gain during the course of a singleton pregnancy for a healthy woman averages 11.5$16 \mathrm{~kg}$, with a weight gain of $1-3 \mathrm{~kg}$ during first trimester and about $0.35-0.5 \mathrm{~kg}$ per week during second and third trimester. ${ }^{3}$

Mothers are subjected to nutritional stress owing to the nursing process and their health risk is multiplied by frequent pregnancies, pregnancy complications like hyperemesis, coupled with a lack of access to and control over income, inadequate education, and excessive demands on their time, and so on. ${ }^{4}$ As in many other countries, there are traditional beliefs in India regarding specific food items a pregnant woman should or should not eat during pregnancy. This leads to misconceptions like the belief of 'eating down' - the belief that pregnant women should eat less than before pregnancy or should not increase the diet during pregnancy quite widespread in India. Foods perceived as 'hot' in Tamil Nadu communities are more in number (papaya, pineapple, mango, animal foods, wheat and sesame seeds). ${ }^{5}$ Awareness of these being myths is not created in women. 
There is an urgent need to overcome the cultural practices that are traditionally affecting the nutritional and health status of women.

There is no doubt that maternal nutrition during pregnancy plays an important role in optimum outcome of pregnancy. The present study was undertaken to study the effects of food habits on pregnancy outcome.

\section{METHODS}

This prospective study was conducted in the Department of Obstetrics and Gynecology, Voluntary Health services, Multi-specialty Hospital and Research Institute, Adyar, Chennai. The study was carried out between January 2013 to July 2014. From the antenatal clinic, 350 women who satisfied the following inclusion and exclusion criteria were admitted to the study. A proper informed consent was obtained from all the mothers who were admitted to the study.

\section{Inclusion criteria}

- All pregnant women less than 40 years with gestational age $<24$ week

- Women willing to come for regular antenatal checkups and delivery at the VHS

- Willing to participate in the study.

\section{Exclusion criteria}

- Maternal complications such as diabetes, hypertension and other medical disorders

- Bad obstetric history

- Not willing to participate in the study.

\section{Methodology}

From the antenatal clinic, 350 women who satisfied the inclusion and exclusion criteria were admitted to the study. At the first visit, a detailed history regarding her present pregnancy was recorded along with a detailed past obstetric history and family history.

All pregnant women who participated in the study were interviewed at regular intervals of (14 to 16 weeks, 24 to 26 weeks, 28 to 30 weeks and 32 to 36 weeks of gestational age). During such visits dietary intake of the subjects was assessed by 24-hour recall method. Maternal weight, hemoglobin and fetal growth profile was noted during such visits. A general physical and obstetric examination was done at such visits. Nutritive value was calculated for every case.

\section{Assessment of food habits}

In this study the dietary intake of the subjects was assessed by 24-hour Recall method.

\section{Follow up}

All the women who participated in the study were called for regular antenatal check-up and care was provided as per the routine protocol. During the regular antenatal check-ups, maternal weight gain, BMI, hemoglobin and fetal growth profile, was assessed. All the women were counseled about the importance of adequate nutrition. The onset of labor spontaneous or induced, type of delivery whether spontaneous vaginal delivery, instrumental vaginal delivery or LSCS was noted.

\section{Perinatal outcome}

The perinatal outcome was assessed by the usual parameters of GA, birth weight, Apgar score and presence or absence of congenital anomalies.

\section{Statistical analysis}

At the end of the study the impact of food habits on pregnancy outcome in terms of mode of delivery, birth weight and NICU admission was assessed and the results were analyzed using appropriate Chi-square statistical method.

\section{Ethical justification}

This study did not involve any invasive procedures. However ethical justification was obtained from the ethical committee of the hospital.

\section{RESULTS}

This prospective study was conducted to study the effects of food habits on pregnancy outcome. This prospective study was conducted in the Department of Obstetrics and Gynecology, Voluntary Health Services, Multi-specialty Hospital and Research Institute, Chennai. The study was carried out between January 2013 to July 2014. From the antenatal clinic, 350 women who satisfied the inclusion and exclusion criteria were admitted to the study

\section{Age distribution}

Age distribution of women who participated in this study is shown in the Table 1.

Table 1: Age distribution.

\begin{tabular}{|ll|}
\hline Age (years) & Total No. $(\%)$ \\
\hline $15-20$ & $30(8)$ \\
\hline $21-25$ & $165(47)$ \\
\hline $26-30$ & $140(40)$ \\
\hline $31-35$ & $15(5)$ \\
\hline Total & 350 \\
\hline
\end{tabular}

From Table 1 it is seen that the maximum number of pregnant women belonged to the age group of 21-25 
years $(47 \%)$ followed by the $26-30$ years age group $(40 \%)$. The number of teenage pregnancies was $30(8 \%)$ whereas $5 \%$ of pregnant women belong the age group of 31-35 years.

\section{Parity}

Half of the pregnant women $(50 \%)$ in the study group were primigravidas and $(43.5 \%)$ were second gravidas. In this study, $6 \%$ and $0.5 \%$ of pregnant women were third and fourth gravidas respectively.

\section{Socio economic status}

The socio-economic status of the respondents as per Kuppuswamy's classification is hsown in Table 2. It is seen from the above table that $83 \%$ of the study population belonged to the low socioeconomic class. $14 \%$ and $3 \%$ of the study population belonged to the upper lower and middle lower socioeconomic class respectively. Majority of women in this study belong to low socioeconomic class this institute provides medical care especially to the patients belonging to the lower socioeconomic class on par with the upper socioeconomic class patients.

Table 2: Socio economic statuses of the pregnant women.

\begin{tabular}{|ll|}
\hline Income group & Total nos $(\%)$ \\
\hline Lower & $290(83)$ \\
\hline Upper lower & $50(14)$ \\
\hline Middle lower & $10(3)$ \\
\hline Total no. & 350 \\
\hline
\end{tabular}

\section{Pre-pregnancy $\mathrm{BMI}$}

\section{Food habits of pregnant mothers}

Depending upon the BMI, the mothers in this study were divided into three major groups. The food items specifically consumed by the pregnant women who participated in this study is shown in the Table 3.

Table 3: Food items specifically consumed by the mothers belonging to different BMI groups.

\begin{tabular}{|llll|}
\hline Food items & $\begin{array}{l}\text { BMI }<18.5 \mathrm{~kg} / \mathbf{m}^{2} \\
\text { \% of mothers }\end{array}$ & $\mathbf{1 8 . 5}-\mathbf{2 4 . 9}$ & $>\mathbf{2 5}$ \\
\hline Rice & 85 & 95 & 90 \\
\hline Milk & 75 & 68 & 54 \\
\hline Idly & 80 & 85 & 70 \\
\hline Rassam & 25 & 17 & 40 \\
\hline Apple & 50 & 47 & 56 \\
\hline Papaya & 00 & 00 & 00 \\
\hline Banana & 75 & 44 & 40 \\
\hline Eggs & 50 & 51 & 60 \\
\hline Dates & 50 & 50 & 60 \\
\hline Mutton soups & 00 & 17 & 40 \\
\hline
\end{tabular}

Table 3 shows the food habits of participant mothers belonging to different BMI groups. In all the three groups the mothers have added the nutritious food items in their diet. In the mothers with low BMI, milk and banana was added by $75 \%$ of mothers followed by apple and dates by $50 \%$ of mothers.

In the mothers with B.M.I within normal range, milk was added by $68 \%$ of mothers followed by apples (47\%), dates $(50 \%)$ and bananas (44\%). Eggs were added by $51 \%$ mothers in their diet.

In the mothers with BMI $>25 \mathrm{~kg} / \mathrm{m}^{2}, 54 \%$ of mothers added milk followed by eggs $(60 \%)$, dates $(60 \%)$ and apples by $56 \%$ of mothers.

\section{Association between the socioeconomic status and calorie intake}

The association between the socioeconomic status and calorie intake of the mothers is shown in the Table 4. The Table 4, shows the association between the calorie intake and socioeconomic status. As shown in Table 4, there is a significant association between the socio-economic status of the mother and the calorie intake.

Table 4: Socioeconomic status and calorie intake.

\begin{tabular}{|lllll|}
\hline SES & $\begin{array}{l}\text { Visit 1 calories } \\
\text { (kcal/kg) }\end{array}$ & Visit 2 & Visit 3 & Visit 4 \\
\hline LIG & 1991.2 & 2063.1 & 2134.4 & 2139.1 \\
\hline MIG & 2036.0 & 2132.2 & 2171.0 & 2179.4 \\
\hline P-value & 0.136 & 0.023 & 0.144 & 0.006 \\
\hline
\end{tabular}

\section{Calorie intake}

The average calorie intake of the mothers belonging to different groups during each visit is shown in Table 5.

Table 5: Average calorie intake.

\begin{tabular}{|lllll|}
\hline BMI & \multicolumn{4}{l}{ Calories $(\mathrm{kcal} / \mathrm{day})$} \\
$\left(\mathrm{kg} / \mathrm{m}^{2}\right)$ & $\begin{array}{l}\mathbf{1 4 - 1 6} \\
\text { weeks }\end{array}$ & $\begin{array}{l}\mathbf{2 4 - 2 6} \\
\text { weeks }\end{array}$ & $\begin{array}{l}\mathbf{2 8 - 3 0} \\
\text { weeks }\end{array}$ & $\begin{array}{l}\mathbf{3 2 - 3 6} \\
\text { weeks }\end{array}$ \\
\hline$<18.5$ & 1640 & 1750 & 2125 & 1950 \\
\hline $18.5-24.9$ & 1800 & 2000 & 2150 & 2100 \\
\hline$>25$ & 1900 & 1950 & 2050 & 2000 \\
\hline
\end{tabular}

The Table 5 shows us the average calorie intake of the mothers belonging to different BMI groups.

The highest calorie intake during the first visit (1900 $\mathrm{kcal} /$ day) was seen in the mothers belonging to the $>25$ $\mathrm{kg} / \mathrm{m}^{2} \mathrm{BMI}$ group, whereas the least calorie intake during the first visit $(1640 \mathrm{kcal} /$ day $)$ was seen in the mothers with BMI $<18.5 \mathrm{~kg} / \mathrm{m}^{2}$. In the mothers belonging to BMI within normal range $\left(18.5-24.9 \mathrm{~kg} / \mathrm{m}^{2}\right)$ the calorie intake during the first visit was $1800 \mathrm{kcal} /$ day. 
In all the three groups there has been a fall in calorie intake during the last visit as compared to the calorie intake in the third visit.

The maximum fall in calorie intake was seen in the mothers with BMI $<18.5 \mathrm{~kg} / \mathrm{m}^{2}$ (1950 kcal/day). The calorie intake in the mothers with BMI within normal range and mothers with $\mathrm{BMI}>25 \mathrm{~kg} / \mathrm{m}^{2}$ was reduced to $2100 \mathrm{kcal} /$ day and $2000 \mathrm{kcal} /$ day respectively.

\section{Mode of delivery of participant mothers}

Maximum number of women $(65 \%)$ had a normal delivery. About $30 \%$ of women underwent a cesarean section. Only $5 \%$ of the pregnant women underwent an instrumental delivery.

\section{Birth weight}

The above tables show the birth weight of the babies in the present study. Majority of the babies $(66 \%)$ had the birth weight in the range of $2.5-2.9 \mathrm{~kg}$. $29 \%$ of babies had birth weight in the range of $3-3.5 \mathrm{~kg}$. $5 \%$ of babies had birth weight in the range of $2-2.49 \mathrm{~kg}$.

\section{Association between the parity and calorie intake}

Table 6 shows the association between parity and the calorie intake of the pregnant women.

Table 6: Parity and calorie intake.

\begin{tabular}{|lllll}
\hline $\begin{array}{l}\text { Parity } \\
\text { code }\end{array}$ & $\begin{array}{l}\text { Visit } 1 \\
\text { calories }\end{array}$ & Visit 2 & Visit 3 & Visit 4 \\
\hline P1 & 1990.3 & 2060.3 & 2127.0 & 2139.1 \\
\hline P2 & 2002.6 & 2084.6 & 2146.2 & 2145.0 \\
\hline P3 & 2050.0 & 2113.2 & 2200.0 & 2206.3 \\
\hline P4 & 1900.0 & 2010.0 & 2140.0 & 2110.0 \\
\hline P-value & 0.050 & 0.297 & 0.035 & 0.335 \\
\hline
\end{tabular}

As per the statistical analysis, there is a significant association between parity and calorie intake during the pregnancy. There is a declining trend in the calorie intake especially in multiparous mothers.

\section{Calorie intake and birth weight}

The association between the calorie intake and birth weight of the baby is shown in the Table 7 .

Table 7: Calorie intake and birth weight.

\begin{tabular}{|llll|l|}
\hline Weight $(\mathrm{kg})$ & Visit 1 & Visit 2 & Visit 3 & Visit 4 \\
\hline $2-2.49$ & 1663.6 & 1795.5 & 1913.6 & 1900.0 \\
\hline $2.5-2.99$ & 1968.2 & 2025.6 & 2117.9 & 2115.8 \\
\hline $3-3.49$ & 2051.4 & 2140.2 & 2183.1 & 2197.6 \\
\hline$\geq 3.5$ & 2018.8 & 2106.3 & 2122.9 & 2129.2 \\
\hline P - Value & 0.000 & 0.000 & 0.000 & 0.000 \\
\hline
\end{tabular}

Table 7 shows the association between the calorie intake of pregnant mother and weight of the baby at birth. As shown in the Table 7 , there is a very significant association between the calorie intake of the mother and birth weight of the baby. Proper calorie intake of the mother has a positive impact on the baby weight.

\section{Calorie intake and NICU admission}

In the present study 3 babies had NICU admission for the fetal distress. The association between the calorie intake of the mother and need for NICU admission for fetal distress is shown in the Table 8 .

Table 8: Association between the calorie intake and NICU admission at birth.

\begin{tabular}{|lllll|}
\hline NICU & Visit 1 & Visit 2 & Visit 3 & Visit 4 \\
\hline Yes & 1987.5 & 2100.0 & 2060.0 & 2097.5 \\
\hline No & 1997.9 & 2072.9 & 2140.7 & 2145.6 \\
\hline P-value & 0.188 & 0.392 & 0.046 & 0.000 \\
\hline
\end{tabular}

\section{Condition at discharge}

All the mothers who participated in this study were discharged on third day in case of a normal delivery and on eighth day in case of a cesarean section.

All the babies including those admitted in NICU were discharged on day 3 after checking their bilirubin levels.

There was no case of neonatal death, postnatal complications like puerperal sepsis and anemia in this study.

\section{DISCUSSION}

An adequate availability of nutrients during gestation is probably the single most important environmental factor influencing pregnancy outcome. ${ }^{1,5}$ Although physiological adjustments in nutrient utilization and metabolism are geared to improve the utilization of dietary nutrients during pregnancy, these adjustments may be insufficient to meet the demands for pregnancy and lactation if the woman is in poor nutrient status at conception. An adequate supply of nutrients is required to maintain the delicate balance between the needs of the mother and those of the fetus. An inadequate supply will cause a state of biological competition between the mother and the conceptus in which the well-being of both is at serious risk. ${ }^{1}$

All societies have traditional beliefs regarding harmful and beneficial foods for women during, pregnancy. ${ }^{6-8}$ There are also beliefs regarding the optimal amount of food to be taken during pregnancy for a successful reproductive outcome. These beliefs may or may not conform to the modern biomedical notions about the proper types and amount of food needed by pregnant women to safeguard maternal nutrition, adequate growth 
of fetus and safe delivery. ${ }^{9,10}$ This prospective study was conducted to study the effects of food habits on pregnancy outcome.

\section{Factors affecting the maternal nutrition}

\section{Socioeconomic status}

In this study majority of the women $(83 \%)$ belonged to lower socioeconomic class as per Kuppuswamy's classification. $14 \%$ of women belonged to upper lower class and $3 \%$ belonged to middle lower socioeconomic class respectively.

The present study found a statistically significant association ( $\mathrm{p}$ value $<0.05$ ) between the socioeconomic status and calorie intake of the mothers. Ayesha et al reported the impact of maternal socioeconomic limitations on the calorie intake. ${ }^{11}$

\section{Parity}

The majority of women in this study were primigravida $(50 \%)$ or second gravida $(43.5 \%)$. $6 \%$ and $0.5 \%$ of women were of birth order 3 and 4 . The present study found a significant association between the parity and maternal calorie intake. Sonneveldt et al reported a statistically significant relationship between the high parity and maternal nutrition. ${ }^{12}$

\section{Food habits and pregnancy outcome}

\section{Mode of delivery}

In the present study $65 \%$ of women delivered normally. $30 \%$ of women underwent a cesarean section and $5 \%$ of women had instrumental deliveries. The present study shows no statistically significant association between the mode of delivery and calorie intake ( $p$ value >0.05). Similar results were found in study conducted by Thilothammal $\mathrm{N}$ and et al. ${ }^{13}$

\section{Birth weight}

In the present study $66 \%$ of the babies had birth weight in the range of $2.5-2.9 \mathrm{~kg}$. $29 \%$ of babies had birth weight in the range of $3-3.5 \mathrm{~kg}$ and $5 \%$ of babies had birth weight in the range of $2-2.49 \mathrm{~kg}$ respectively. The present study found a very significant association between the maternal calorie intake and birth weight of the baby. Sumithra M, Stephenson et al demonstrated maternal nutritional status as a very important determinant of birth weight. ${ }^{14,15}$

\section{NICU admission}

In the present study 3 babies had NICU admission for fetal distress. The present study found a statistically significant association between the maternal calorie intake and the NICU admission. Kalik P et al and Minsart et al found similar statistically significant results. ${ }^{16}$
The mothers whose pre-pregnancy BMI was low were given nutritional advice and it was noted that there was a marginal increase in their caloric intake in subsequent visits. However, this is not sufficient to influence the pregnancy outcome. All these mothers belonging to low SE group are covered under the ICDS scheme and receive nutritional supplement during the entire pregnancy

\section{CONCLUSION}

Among the 350 women who participated in this study majority of the women belonged to the age group of 2130 years and to a lower socioeconomic class with the prepregnancy BMI within normal range of $18.5-24.9 \mathrm{~kg} / \mathrm{m}^{2}$.

The average calorie intake of mothers with normal BMI was $2012 \mathrm{kcal} / \mathrm{day}$. The average calorie intake of mothers with BMI $<18.5 \mathrm{~kg} / \mathrm{m}^{2}$ and mothers with B.M.I $>25$ was $1866 \mathrm{kcal} /$ day and $1975 \mathrm{kcal} /$ day respectively.

The food items consumed by the mothers during pregnancy consisted of rice, sambhar, milk, idly, fruits like apple, banana, dates, rassam and mutton soups. There was a significant association ( $p$ value $<0.05$ ) between the socioeconomic status of the mother, parity and her calorie intake. The present study found a statistically significant association between the maternal nutritional status, the birth weight of the baby and the need for NICU admission ( $p$ value $<0.05$ ).

Maternal food habits have an impact on the pregnancy outcome. Nutrition education and awareness generation among the women is needed. ${ }^{18,19}$ Maternal food habits are influenced by many factors like socioeconomic status, parity, social food taboos and pregnancy itself. The pregnancy outcomes like birth weight, need for NICU admission and postnatal complications are influenced by maternal nutritional status.

\section{ACKNOWLEDGMENTS}

This research was supported by the VHS Hospital. Author would like to thank all his professors and Colleagues from the VHS for their support. Author would especially like to thank his HOD Dr S. Janaki, Prof. Ratnakumar, Dr. Sarala Gopalan, Dr. Esakiammal and Dr Naseem P. Amir for their assistance with methodology and for comments that greatly improved the manuscript.

Funding: No funding sources

Conflict of interest: None declared

Ethical approval: The study was approved by the Institutional Ethics Committee

\section{REFERENCES}

1. King JC. The risk of maternal nutritional depletion and poor outcomes increases in early or closely spaced pregnancies. J Nutr. 2003;133(5):1732S-6S. 
2. MOHFW. National family health survey-4. International institute for population sciences. Mumbai; 2015-2016.

3. Institute of Medicine. Weight gain during pregnancy: reexamining the guidelines. Washington, DC: National Academy Press; 2009.

4. Asha K, Salil S. Nutrient intake of lactating mothers from rural areas and urban areas. Indian J Soc Res. 1998;39:2.

5. Nag M. Beliefs and practices about food during pregnancy: implications for maternal nutrition. Economic Political Weekly. 2009;29(37):2427-38.

6. Zeisel HS. Importance of methyl donors during reproduction. Am J Clin Nutr. 20009;89(2):673S-7.

7. Wahid MA, Fathi SA. Nutrition and the unborn baby. Ric Clin Lab. 1987;17(3):199-206.

8. Manderson L, Mathews M. Vietnamese attitudes towards maternal and infant health. Med J Aust. 1981:69-72.

9. Mitchell J, Mackerras D. The traditional humoral food habits of pregnant Vietnamese-Australian women and their effect on birth weight. Aust J Public Health.1995:629-33.

10. Patil R, Mittal A, Vedapriya D, Khan MI, Raghavia M. Taboos and misconceptions about food during pregnancy among rural population of Pondicherry. Calicut Med J. 2010;8(2):e4.

11. Rizvi F. Impact of maternal education, and socioeconomic status on maternal nutritional knowledge and practices regarding iron rich foods and iron supplements. Ann Pak Inst Med Sci. 2012;8(2):101-5.

12. Sonneveldt E, Plosky WD, Stover J. Linking high parity and maternal and child mortality: what is the impact of lower health services coverage among higher order births. BMC Public Health. 2013;13(3):S7.

13. Thilotthammal $\mathrm{N}$. Influence if maternal nutritional status on mode of delivery and asphyxia neonatorum. Indian J Pediatr. 1992;59(3):325-9.

14. Sumithra M. Maternal nutrition and low birth weight-what is really important. Indian J Med Res. 2009;130:600-8.

15. Stephenson T, Symonds M. Maternal nutrition as a determinant of birth weight. Arch Dis Child Fetal Neonatal Ed. 2002;86:F4-F6.

16. Kalik P, Guthmann F, Krause K, Relle K, Godes M, Gossing $\mathrm{G}$, et al. Impact of maternal body mass index on neonatal outcome. Eur $\mathrm{J}$ Med Res. 2009;14(5):216-22.

17. Minsart AF, Buekens P, De Spiegelaere M, Englert Y. Neonatal outcomes in obese mothers: a population-based analysis. BMC Pregnancy Childbirth. 2013;13:36.

18. Eram U, Tamanna Z, Humaira JT. Taboos and misconceptions associated with pregnancy among rural women in Aligarh. Int $\mathbf{J}$ Inform Res Rev. 2016;03(12):3407-9.

19. Ugwa EA. Nutritional practices and taboos among pregnant women attending antenatal care at general hospital in Kano, Northwest Nigeria. Ann Med Health Sci Res. 2016;6(2):109-14.

Cite this article as: Pitale DL. The effects of food habits on pregnancy outcome. Int J Reprod Contracept Obstet Gynecol 2018;7:622-7. 